\title{
Creutzfeldt-Jakob disease with Alzheimer pathology, presenting with status epilepticus following repeated partial seizures: a case report and literature review
}

Keita Miyake ${ }^{1}$, Takashi Hara², Etsuko Oshima', Kiyohiro Kawada', Hideki Ishizu ${ }^{3}$, Yuko Yamauchi ${ }^{3}$, Katsuya Satoh ${ }^{4}$, Tetsuyuki Kitamoto ${ }^{5}$, Shintaro Takenoshita ${ }^{1}$, Seishi Terada ${ }^{1 *}$ and Norihito Yamada ${ }^{1}$

\begin{abstract}
Background: Creutzfeldt-Jakob disease (CJD) is a fatal neurodegenerative disease. Common first symptoms are dementia, cerebellar ataxia, visual disturbance, and psychiatric symptoms. Seizure as the first symptom of CJD is a very rare finding.
\end{abstract}

Case presentation: We experienced an elderly woman who presented initially with status epilepticus following repeated partial seizures in the course of Alzheimer disease (AD) dementia. Anti-convulsive therapy had no effect. Autopsy revealed definite CJD with AD pathology.

Coclusions: This is the first reported CJD case presenting with status epilepticus in the course of AD dementia.

Keywords: Alzheimer disease, Creutzfeldt-Jakob disease, Epilepsy, Seizure, Status epilepticus

\section{Background}

Creutzfeldt-Jakob disease (CJD) is a fatal neurodegenerative disease affecting humans and a wide variety of animals. Most cases are sporadic with an unknown etiology. The incidence of CJD is approximately one case per million person per year [1]. The typical presentations include rapidly progressive cognitive decline, behavioral changes, cerebellar dysfunction, and visual disturbances [1]. Epilepsy is an uncommon feature in patients with CJD [2]. Here, we report an elderly woman with CJD who presented initially with status epilepticus (SE) following repeated partial seizures during the course of Alzheimer disease dementia (ADD).

\section{Case presentation}

The patient was a Japanese woman who was 82 years and 1 month old at the time of death. She had no family history of dementia, and had not received dura mater

\footnotetext{
* Correspondence: terada@okayama-u.ac.jp

${ }^{1}$ Department of Psychiatry, Okayama University Graduate School of Medicine, Dentistry, and Pharmaceutical Sciences, 2-5-1 Shikata-cho, Kita-ku, Okayama 700-8558, Japan

Full list of author information is available at the end of the article
}

transplantation. Medical history of the patient are summarized on a timeline (Fig. 1).

She developed memory disturbance at the age of 79 and became unable to pay invoices. She sometimes complained of money being stolen, and had a check-up at memory clinic. The scores of the Mini Mental State Examination and Hasegawa Dementia Scale Revised were $19 / 30$ and $14 / 30$, respectively. She was diagnosed with ADD, and started to take donepezil orally at the age of 80 years and 8 months. For 13 months after the start of donepezil treatment, no remarkable changes were observed in her cognitive and motor function.

At the age of 81 years and 9 months, she became unable to move her right hand well, and her right arm sometimes elevated involuntarily. She declined into a twilight state gradually over two weeks. She spoke ambiguously and did not make eye contact. Head CT showed no remarkable change. She was hospitalized in a ward for patients with dementia in a psychiatric hospital. She had no fever. Electroencephalogram (EEG) showed spikes in the left parietal region, and slow wave bursts in the bilateral frontal areas. Tonic convulsion in the right 


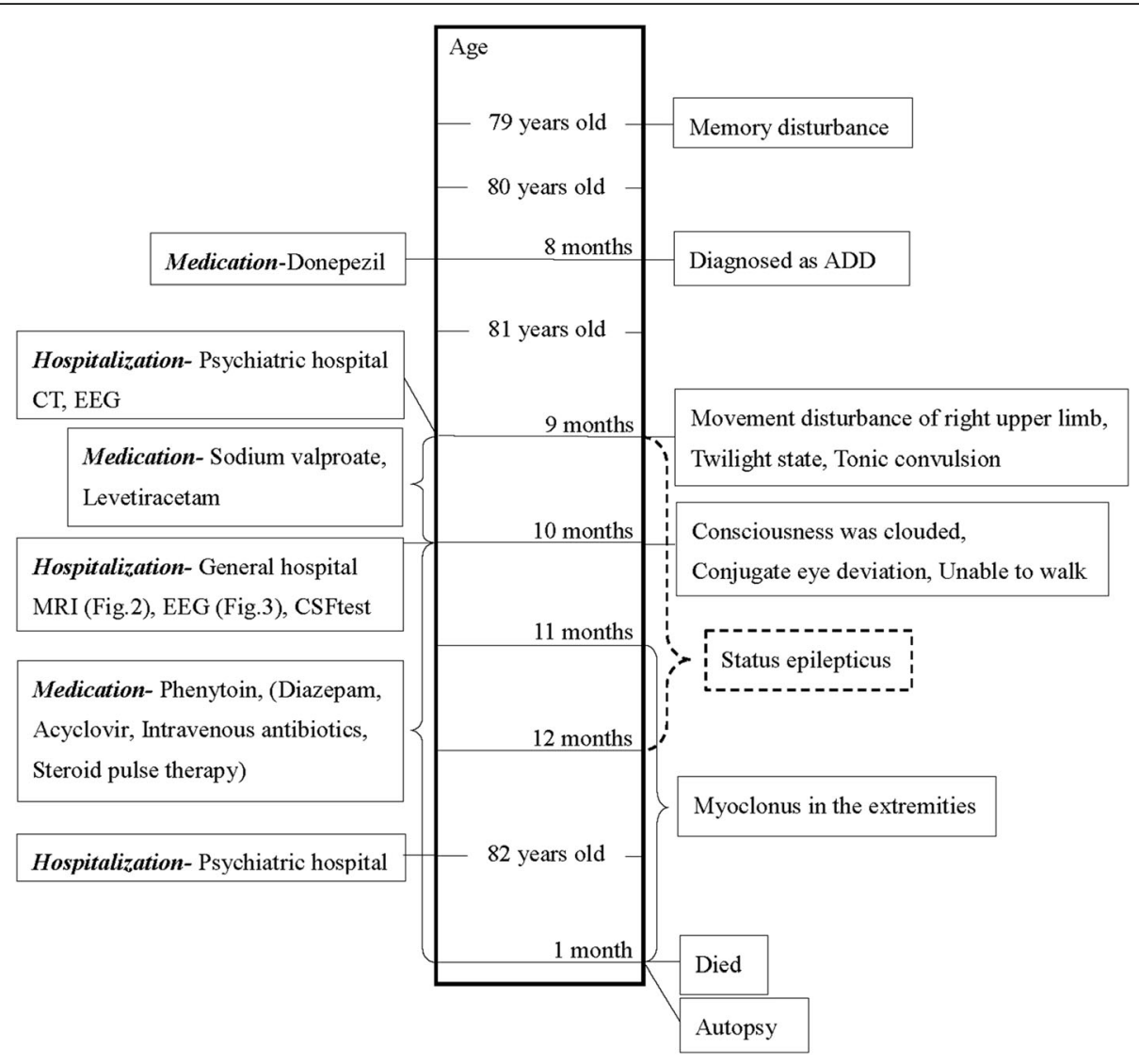

Fig. 1 Medical history of the patient displayed on the timeline

upper extremity occurred several times a day. Sodium valproate $(400 \mathrm{mg} /$ day $)$ and levetiracetam $(1000 \mathrm{mg} /$ day $)$ were started. Her consciousness level fluctuated and was not clear all day, and she gradually became unable to walk. One week after admission, at the age of 81 years and 10 months, she was transferred to a general hospital.

Consciousness was clouded, and she was bed-ridden. Body temperature was 38.1 degrees. The Glasgow coma scale score was 7 (eye opening 3, verbal response 1, motor response 3 ), and the Japan coma scale score was 30 . The right upper extremity was held in a flexed posture and did not move. The left upper extremity and bilateral lower extremities moved voluntarily. Deep tendon reflex was within normal range, and Babinski sign was negative. Conjugate eye deviation to the right and tonic convulsion in the right upper limb for a few minutes was observed about ten times a day.

Cerebrospinal fluid (CSF) examination revealed a normal initial pressure $(180 \mathrm{mmHg})$, normal cell count $(3 / 3)$, slightly elevated protein level $(65 \mathrm{mg} / \mathrm{dl})$, and normal sugar level $(45 \mathrm{mg} / \mathrm{dl})$. The IgG index was low (0.375), and the neuron-specific enolase concentration in CSF was elevated $(44.24 \mathrm{ng} / \mathrm{ml})$. Anti-thyroid peroxidase and antithyroglobulin antibodies were negative. Head diffusion magnetic resonance imaging (MRI) showed ribbon-like high intensity areas, separately in the cortex of the left temporo-parietal lobe, right parietal lobe, left frontal lobe, left insula, and left basal ganglia (Fig. 2). T1- and T2weighted images of the head MRI showed no remarkable lesions except for the severe bilateral hippocampal atrophy (VSRAD advance: severity of hippocampal atrophy, 2.62) [3]. EEG showed diffuse periodic slow waves, similar to periodic lateralized epileptiform discharges, in the left hemisphere dominantly.

SE was strongly suspected, and intensive anti-convulsive therapy with intravenous phenytoin and diazepam suppository was started. Additionally, intravenous antibiotics and acyclovir were used for a week. However, no remarkable improvement was observed in the state of the patient. Tonic convulsion in the right upper limb with a decrease of oxygen saturation for a few minutes several times a day was observed throughout the course. Steroid pulse therapy for three days was performed twice, but had no effect. Gradually tonic convulsion decreased, and myoclonus appeared in the lower extremities. The EEG evolved into a more generalized periodic synchronous discharge (PSD) (Fig. 3).

One month later, she was returned to a psychiatric hospital at the age of 81 years and 11 months. She 


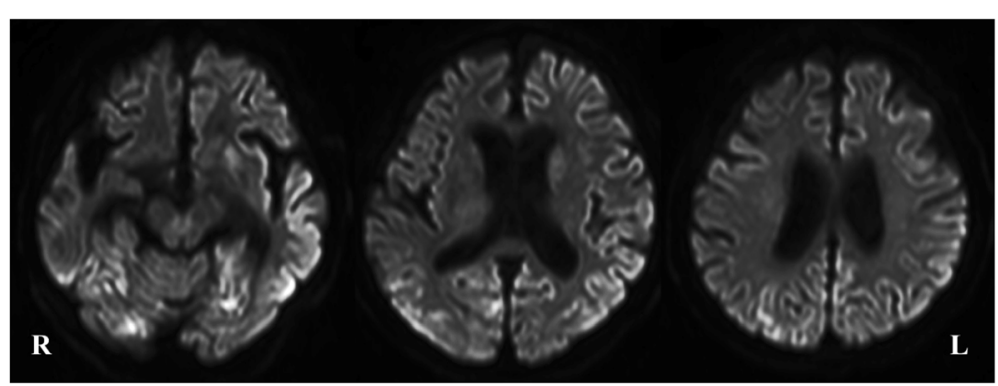

Fig. 2 Head MRI (axial, diffusion-weighted image) of the patient. Diffusion-weighted brain images showed high intensity lesions, separately in the cortex of the left temporo-parietal lobe, right parietal lobe, left frontal lobe, left insula, and left basal ganglia

developed akinetic mutism at the age of 82 years, and she died at the age of 82 years and one month.

An autopsy was done three hours after death, and the brain weight was $980 \mathrm{~g}$. Macroscopically, diffuse cortical atrophy was found. No atrophy was observed in the cerebellum or the white matter of the cerebrum. Microscopically, early lesions with typical spongiform changes in the cerebral cortex were found diffusely, and slight vacuolations were observed in the frontal and occipital lobes. An immunohistochemical study for prion protein showed synaptic deposition diffusely in the cerebrum, and a slightly perivacuolar pattern was observed in the frontal and occipital lobes. In the cerebellum, slight spongiform changes were found in the molecular layer of the cerebellum, and synaptic depositions of prion protein were observed. AD-related neurofibrillary pathology of this case was Stage IV-V, and the amyloid phase was Phase $5[4,5]$.

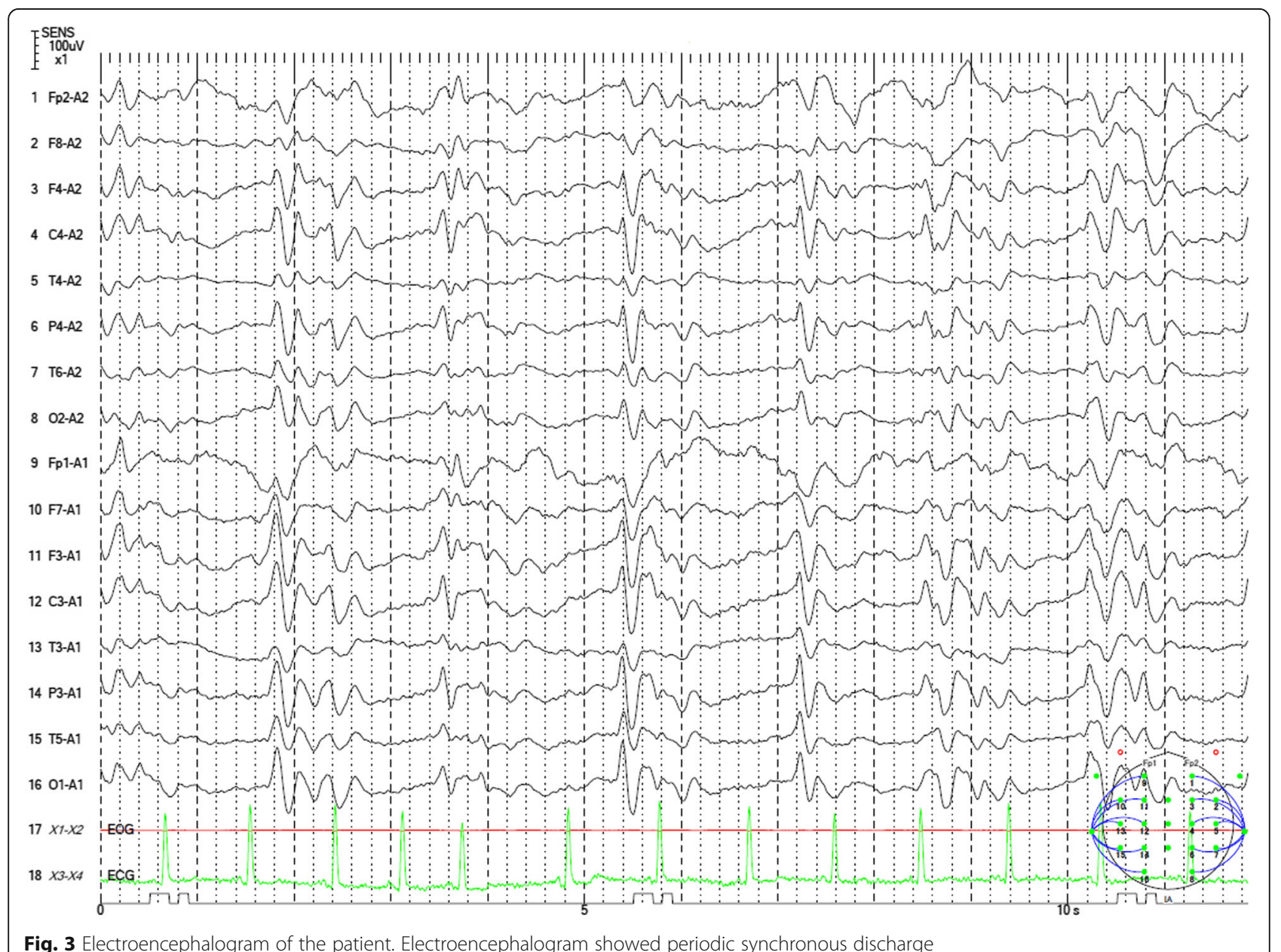

Fig. 3 Electroencephalogram of the patient. Electroencephalogram showed periodic synchronous discharge 
Table 1 CJD patients who presented with partial seizures as an initial symptom

\begin{tabular}{llllllll}
\hline Case & Age & Sex & Seizures & Automatism & Effect $^{\text {a }}$ & Autopsy $^{\text {b }}$ & Type $^{c}$ \\
\hline Rees et al., 1999 [15] & 58 & F & CPS & $(-)$ & $(-)$ & autopsy & nm \\
Rees et al., 1999 [15] & 68 & M & CPS & $(-)$ & $(-)$ & $(-)$ & $(-)$ \\
Lee et al., 2000 [16] & 42 & M & CPS, EPC & jerky movement of right arm & $(-)$ & biopsy & nm \\
Parry et al., 2001 [17] & 67 & F & EPC & flailing of the left upper limb & $(+)$ & autopsy & nm \\
Neufeld et al., 2003 [18] & 62 & M & SPC, SGS & $(-)$ & $(-)$ & autopsy & E200K \\
Ogawa et al., 2011 [19] & 61 & F & CPS & hand and oral automatism & $(-)$ & $(-)$ & $(-)$ \\
Miyake et al., 2017 & 82 & F & CPS & elevation of right arm & $(-)$ & autopsy & MM1 \\
\hline
\end{tabular}

Effect $^{\mathrm{a}}$, effect of anti-epileptics; Autopsy ${ }^{\mathrm{b}}$, autopsy or biopsy; Type $^{\mathrm{c}}$, type of CJD

CPS complex partial seizure, EPC epilepsia partialis continua, SPC simple partial seizure, SGS secondary generalized seizure, $\mathrm{nm}$ not mentioned

Genetic testing showed no mutations and a 129Met/ Met, 219Glu/Glu pattern in the prion protein gene. Western blot showed an MM1 pattern. In the CSF, 14-3-3 protein was negative, and RT-QuIC of prion protein was positive. The genotype of apolipoprotein $\mathrm{E}$ was e3/e4.

\section{Discussion and conclusion}

The coexistence of $\mathrm{AD}$ pathology and prion pathology in the same case is uncommon [6]. Brown et al. presented a synopsis of a National Institute of Health series of 189 CJD cases autopsied during the past 30 years, and only four of them were found to exhibit evidence of AD pathology [7]. Tsuchiya et al. stated that there were two forms of coexistence of CJD and AD [8]. The first type is $\mathrm{AD}$ cases developing $\mathrm{CJD}$ in the late stage of $\mathrm{AD}$, and the second is CJD having AD pathology without clinical features of $\mathrm{AD}$ [8]. Our case corresponds to the first form.

$\mathrm{AD}$ is associated with a high risk for developing epileptic seizures [9]. AD and other neurodegenerative conditions represent the presumed etiology for $10 \%$ of new onset epilepsy in patients older than 65 [10]. Therefore, in the beginning, we suspected epileptic seizures due to $\mathrm{AD}$ in this case. Because anti-epilepticus treatment had no effect and a gradually worsening consciousness level was observed, we reconsidered the cause of the seizures and suspected other conditions such as encephalitis or encephalopathy.

Although about $70 \%$ of aged patients with SE were without a previous diagnosis of epilepsy, diffusion-weighted hyperintensities associated with SE were observed in $28 \%$ of patients (26 of 93 patients) [11]. A ribbon-like high intensity area in the cerebral cortex on diffusion-weighted images might be induced by SE [11]. Therefore, we broadly examined the cause of SE and performed intensive anti-convulsive therapy. However, there was no obvious effect.

As stated above, Yoshimura et al. found abnormal hyperintensities on diffusion-weighted images in $28 \%$ of the patients with SE [11]. In 25 of the 26 patients, diffusion-weighted hyperintensities were unilateral. Only one case had bilateral thalamic lesions. In our case, diffusion-weighted hyperintensities were found separately in left temporo-parietal, right parietal, left frontal lobes, left insula, and left basal ganglia. If the case showed bilateral diffusion-weighted hyperintensities, we had better consider a cause other than simple SE.

In two large surveillance reports contaning 674 or 492 sporadic CJD cases, there was no case with an epileptic seizure as the first symptom of CJD [12,13]. Only two of 492 sporadic CJD cases showed myoclonus as the first symptom [13]. In 264 patients initially suspected of having prion disease but finally judged not to, 18 cases were diagnosed as epilepsy and two were diagnosed as $\mathrm{AD}$ and epilepsy [14]. It was difficult for us to diagnose CJD in the early stage because we did not recognize the presence of rapidly progressive dementia due to SE. After the appearance of the myoclonic jerk in the lower extremities and PSD on EEG, we diagnosed her as having probable CJD.

Seven patients with CJD who presented with partial seizures as an initial symptom have been reported (Table 1). In most cases, anti-convulsive therapy had no effect. Our patient was much older than the other six cases, and was the only case who suffered from early partial seizures due to CJD during the course of ADD. Like the previous reports, no pathological differences were found between the epileptogenic region and other cortices $[15,17,18]$. Although complex partial seizures and SE are rare in CJD, we should consider CJD in the differential diagnosis in aged patients with SE.

\section{Abbreviations}

AD: Alzheimer disease; ADD: Alzheimer disease dementia; CJD: CreutzfeldtJakob disease; CSF: Cerebrospinal fluid; EEG: Electroencephalogram; MRI: Magnetic resonance imaging; PSD: Periodic synchronous discharge; SE: Status epilepticus

\section{Acknowledgements}

The authors thank the patient and her daughter for their collaboration.

\section{Funding}

This study is partly supported by a grant from the Zikei Institute of Psychiatry. 


\section{Availability of data and materials}

The datasets used and/or analysed during the current study are available from the corresponding author on reasonable request.

\section{Authors' contributions}

$\mathrm{KM}, \mathrm{TH}, \mathrm{EO}$ and $\mathrm{KK}$ provided treatment to the patient, collected the data and wrote the draft. $\mathrm{HI}$ and $\mathrm{YY}$ performed autopsy, collected the data and were involved in drafting the manuscript. KS and TK preformed the clinical and genetic examination, and revised the manuscript critically. KM, STa, STe and NY participated in the design of the case report and wrote the manuscript. All authors read and approved the final manuscript.

\section{Ethics approval and consent to participate}

This case report was approved by the Ethical Committee of the Okayama University Graduate School of Medicine, Dentistry and Pharmaceutical Sciences and Zikei Institute of Psychiatry. Autopsy and gene analysis were carried out after written informed consent was obtained from the daughter of the patient

\section{Consent for publication}

Written informed consent was obtained from the daughter of the patient for publication of this Case Report and any accompanying images. A copy of the written consent is available for review by the Editor of this journal.

\section{Competing interests}

The authors declare that they have no competing interests.

\section{Publisher's Note}

Springer Nature remains neutral with regard to jurisdictional claims in published maps and institutional affiliations.

\section{Author details}

'Department of Psychiatry, Okayama University Graduate School of Medicine, Dentistry, and Pharmaceutical Sciences, 2-5-1 Shikata-cho, Kita-ku, Okayama 700-8558, Japan. '2Department of Psychiatry, Hayashi Hospital, Okayama, Japan. ${ }^{3}$ Department of Psychiatry, Zikei Hospital, Okayama, Japan. ${ }^{4}$ Department of Locomotive Rehabilitation Sciences, Nagasaki University Graduate School of Medicine, Nagasaki, Japan. ${ }^{5}$ Department of Neurological Science, Tohoku University Graduate School of Medicine, Sendai, Japan.

\section{Received: 28 September 2017 Accepted: 18 April 2018}

\section{Published online: 25 April 2018}

\section{References}

1. Johnson RT. Prion diseases. Lancet Neurol. 2005;4(10):635-42.

2. Wieser HG, Schindler K, Zumsteg D. EEG in Creutzfeldt-Jakob disease. Clin Neurophysiol. 2006;117(5):935-51.

3. Matsuda H, Mizumura S, Nemoto K. Automatic voxel-based morphometry of structural MRI by SPM8 plus diffeomorphic anatomic registration through exponentiated lie algebra improves the diagnosis of probable Alzheimer disease. Am J Neuroradiol. 2012;33(6):1109-14.

4. Braak H, Alafuzoff I, Arzberger T, Kretzschmar H, Del Tredici K. Staging of Alzheimer disease-associated neurofibrillary pathology using paraffin sections and immunocytochemistry. Acta Neuropathol. 2006;112(4):389-404.

5. Thal DR, Rüb U, Orantes M, Braak H. Phases of a beta-deposition in the human brain and its relevance for the development of AD. Neurology. 2002; 58(12):1791-800

6. Yoshida H, Terada S, Ishizu H, Ikeda K, Hayabara T, Ikeda K, Deguchi K, Touge T, Kitamoto T, Kuroda S. An autopsy case of Creutzfeldt-Jakob disease with a V180l mutation of the PrP gene and Alzheimer-type pathology. Neuropathology. 2010;30(2):159-64.

7. Brown P, Jannotta F, Gibbs CJ Jr, Baron H, Guiroy DC, Gajdusek DC. Coexistence of Creutzfeldt-Jakob disease and Alzheimer's disease in the same patient. Neurology 1990;40(2):226-228.

8. Tsuchiya K, Yagishita S, Ikeda K, Sano M, Taki K, Hashimoto K, Watabiki S, Mizusawa $\mathrm{H}$. Coexistence of CJD and Alzheimer's disease: an autopsy case showing typical clinical features of CJD. Neuropathology. 2004;24(1):46-55.

9. Horváth A, Szúcs A, Barcs G, Noebels JL, Kamondi A. Epileptic seizures in Alzheimer disease: a review. Alzheimer Dis Assoc Disord. 2016;30(2):186-92.

10. Pandis D, Scarmeas N. Seizures in Alzheimer disease: clinical and epidemiological data. Epilepsy Curr. 2012;12(5):184-7.
11. Yoshimura H, Matsumoto R, Ueda H, Ariyoshi K, Kawamoto M, Ishii J, Ikeda A, Takahashi R, Kohara N. Status epilepticus in the elderly: prognostic implications of rhythmic and periodic patterns in electroencephalography and hyperintensities on diffusion-weighted imaging. J Neurol Sci. 2016;370:284-9.

12. Nagoshi K, Sadakane A, Nakamura Y, Yamada M, Mizusawa H. Duration of prion disease is longer in Japan than in other countries. J Epidemiol. 2011;21(4):255-62.

13. Krasnianski A, Kaune J, Jung K, Kretzschmar HA, Zerr I. First symptom and initial diagnosis in sporadic CJD patients in Germany. J Neurol. 2014;261(9):1811-7.

14. Nozaki I, Hamaguchi T, Sanjo N, Noguchi-Shinohara M, Sakai K, Nakamura Y, Sato T, Kitamoto T, Mizusawa H, Moriwaka F, Shiga Y, Kuroiwa Y, Nishizawa M, Kuzuhara S, Inuzuka T, Takeda M, Kuroda S, Abe K, Murai H, Murayama S, Tateishi J, Takumi I, Shirabe S, Harada M, Sadakane A, Yamada M. Prospective 10-year surveillance of human prion diseases in Japan. Brain. 2010:133(10):3043-57.

15. Rees JH, Smith SJ, Kullmann DM, Hirsch NP, Howard RS. Creutzfeldt-Jakob disease presenting as complex partial status epilepticus: a report of two cases. J Neurol Neurosurg Psychiatry. 1999;66(3):406-7.

16. Lee $\mathrm{K}$, Haight E, Olejniczak P. Epilepsia partialis continua in Creutzfeldt-Jakob disease. Acta Neurol Scand. 2000;102(6):398-402.

17. Parry J, Tuch P, Knezevic W, Fabian V. Creutzfeldt-Jakob syndrome presenting as epilepsia partialis continua. J Clin Neurosci. 2001;8(3):266-8.

18. Neufeld MY, Talianski-Aronov A, Soffer D, Korczyn AD. Generalized convulsive status epilepticus in Creutzfeldt-Jakob disease. Seizure. 2003;12(6):403-5.

19. Ogawa K, Yoshihashi H, Suzuki Y, Oishi M, Kamei S. Case of probable Creutzfeldt-Jakob disease presenting with complex partial seizure following sleeplessness and cognitive impairment. Geriatr Gerontol Int. 2011;11(2):229-32

\section{Ready to submit your research? Choose BMC and benefit from:}

- fast, convenient online submission

- thorough peer review by experienced researchers in your field

- rapid publication on acceptance

- support for research data, including large and complex data types

- gold Open Access which fosters wider collaboration and increased citations

- maximum visibility for your research: over $100 \mathrm{M}$ website views per year

At BMC, research is always in progress.

Learn more biomedcentral.com/submissions 